\title{
Metodologias de uso de jogo computacional RPG em sala de aula: estudo de caso com o jogo PeaceMaker
}

\author{
Sidnei Alves Ferreira Junior - Instituto Federal de Goiás - sidneijunior@live.com \\ Márcio Gomes Pacheco - Instituto Federal de Goiás - marcioafp@ hotmail.com \\ Carlos Roberto da Silveira Junior - Instituto Federal de Goiás - \\ carlos.junior@ifg.edu.br \\ Alex Santos Bandeira Barra - Instituto Federal de Goiás - alexbarrago@yahoo.com.br
}

Resumo: Os educadores precisam elaborar meios dinâmicos que possam melhorar o ensino de conteúdos no currículo escolar. Aliado à interdisciplinaridade, a utilização de ferramentas lúdicas, como jogos computacionais, reforçam, de maneira considerável, o aparato educacional e as estratégias de aplicação de conteúdo. Esse artigo tem como objetivo apresentar metodologias de uso de jogos educacionais, classificados como RPG, na escola, tendo como estudo de caso com o jogo PeaceMaker. Para tanto foram propostas três planos de aula para realização de atividade teórica e prática com alunos. Foram aplicados questionários antes e após a atividade, sendo apresentados resultados relevantes para atividades em intervalos maiores no tempo e com prática e teoria intercalados.

Palavras-chave: Interdisciplinaridade, Jogo RPG, PeaceMaker Game

Abstract: Educators need to create dynamic means that can improve the teaching of content in the school curriculum. In addition to interdisciplinarity, the use of play tools, such as computer games, considerably reinforces the educational apparatus and the strategies of content application. This article aims to present methodologies of use of educational games, classified as RPG, in the school, having as case study the game PeaceMaker. For that, three different methodologies were proposed to carry out theoretical and practical activity with students. Quiz were applied before and after the activity, and relevant results were presented for activities at longer time intervals and with interspersed practice and theory.

Keywords: interdisciplinarity, Serious Game, PeaceMaker Game

\section{Introdução}

Todos os dias, quando um professor elabora seu plano de aula, ele se coloca diante de várias possibilidades de elaboração de estratégias para melhor apresentar o conteúdo proposto, com foco no aprendizado dos alunos. Independente da concepção pedagógica, ele é desafiado a despertar o interesse de seus alunos para motivá-los a participarem, de forma ativa, do desenvolvimento da matéria.

Uma necessidade do educador moderno é adequar suas estratégias didáticas à visão de mundo de seus alunos. A partir da década de 80, com grandes avanços tecnológicos, passou-se a perceber também mudanças gradativas nas relações (entre professor e aluno) em sala de aula. Foi quando se passou a fazer uso, de maneira mais acentuada, de novos instrumentos que serviam de apoio pedagógico, como o videocassete, a TV, o retroprojetor, etc (Moraes, 2000).

Uma das alternativas pedagógicas que possibilitam o interesse do aluno a respeito do conteúdo que se deseja explorar em sala de aula é a possibilidade de diálogo 
entre diferentes disciplinas. Assim, determinado assunto pode, ao mesmo tempo, ser trabalhado através de diferentes óticas por professores que, em caráter de parceria, desenvolvem a apresentação dos tópicos a partir do viés proposto por sua própria disciplina.

Segundo Oliveira (1977), a aplicação de recursos tecnológicos à educação surge no Brasil buscando alcançar um aprimoramento das práticas didáticas através de técnicas provenientes dos meios de comunicação em massa. A partir da década de 60 se expande o sistema de ensino e das tecnologias no campo educacional, surgindo, conceitos como o da educação à distância, como os cursos técnicos oferecidos pelo Instituto Universal Brasileiro e, posteriormente, o Telecurso $2^{\circ}$ grau e Telecurso 2000, desenvolvido pela Rede Globo de Telecomunicações. O uso das mídias mostrou-se fundamental para o aprimoramento educacional desde que não esteja atrelado a uma forma neutra e instrumental de ensino, tal qual divulgado pela chamada pedagogia tradicional (Saviani, 1984; Meksenas, 2007).

Esse desenvolvimento tecnológico, ainda tímido a princípio, despercebidamente foi alterando a maneira convencional com que a educação historicamente era concebida: um professor e seus alunos dentro de uma sala de aula, munidos de livros, cadernos e um quadro de giz. A prática docente foi paulatinamente alterada pela entrada das tecnologias na escola. O professor atual, embora mantenha certa maneira tradicional de ensinar, baseada na transmissão do conhecimento, já tem maior aproximação com os alunos. $\mathrm{O}$ aluno é visto de maneira mais participativa no processo de aprendizagem, além do que o uso das mídias favorece a apresentação da "imagem" facilitando a visualização dos conceitos de maneira mais clara (Piaget, 1974).

A partir do final do século XIX, as discussões se centram no novo papel do aluno, surgindo o movimento da escola nova. Este movimento surge como crítica a concepção que toma o professor como centro do saber e detentor real do conhecimento. Conforme aponta Saviani (1984), a pedagogia nova desloca o professor como centro do conhecimento, para o aluno, pois esta nova corrente supõe que a ignorância do aluno não é um problema apenas da transmissão do conhecimento, mas sim de sua rejeição.

Um grande desafio existente na atualidade é, justamente, a busca de se adequar as estratégias didáticas para alunos que já nasceram no contexto em que a sociedade está envolvida de tecnologia. É a geração conhecida como nativos digitais (Mattar, 2010) e para a qual existe o desafio de se repensar a maneira tradicional de exposição do assunto que se propõe ensinar. Nesse contexto, jogos computacionais permitem uma grande amplitude de atividades educacionais em diferentes disciplinas, permitindo vivência do assunto tratado e, mais importante, reflexão e aprendizado em grupo.

Como exemplo, têm-se jogos RPG (Role-Playing Game) onde o jogador assume o papel de protagonista e deve realizar tarefas com o intuito de obter informações ou poderes para continuar o jogo. Um exemplo de jogo RPG com caráter educacional, famoso na década de 90, foi a série Carmem Sandiego, em que o jogador visitava vários lugares ao redor do mundo para prender bandidos (dentre eles a principal vilã, que dá nome ao jogo) conhecendo diversos países e testando seus conhecimentos de geografia, história, línguas, matemática e lógica, indo além da dinâmica de perguntas e respostas (Tech Mundo, 2017).

Atividades assim precisam de um tempo maior para o desenvolvimento, uma vez que necessitam de etapas para apresentação da teoria, explanação do jogo e para que os alunos joguem e se envolvam com a atividade, ocorrendo assim o aprendizado. Porém, o tempo representa uma das dificuldades inerentes para realização desse tipo de atividade em sala de aula: muitas vezes o professor não pode realizar a atividade durante as aulas curriculares, por não fazer parte diretamente do plano de aulas da disciplina, 
sendo necessário realizar durante eventos científicos ou finais de semana. Além disso, devido o horário de aula dos professores fica difícil envolver outros professores na atividade se for desenvolvida no horário de aula de uma determinada sala de aula.

Assim, ocorre a necessidade de avaliar como realizar o plano de atividade no tempo e quando apresentar o jogo durante a execução da atividade: um único dia (por exemplo, em dia de evento científico), dias nos finais de semana (sábados), intercalados por atividades teóricas ou práticas durante a semana. Esse artigo tem como objetivo apresentar alternativas de metodologias, baseadas em planos de aula, de uso de jogos educacionais, classificados como RPG (Role-Playing Game), tendo como estudo de caso o jogo PeaceMaker.

\section{Sobre o jogo}

O jogo Peacemaker foi implementado por dois estudantes sendo um ex-oficial de inteligência israelense, Asi Burak de 35 anos e o desenvolvedor de software, Eric Brown de 29 anos, no curso superior de Informática pela Universidade americana de Carnegie Mellon, eles criaram uma empresa com o nome de Impact Games e publicaram o PeaceMaker Game. Para o desenvolvimento do jogo, com o intuito de aproximar o comportamento do jogo com a realidade (social, política, histórica e cultural), tiveram auxilio de consultores americanos, israelenses e palestinos (Peacemaker, 2014).

Esse jogo é categorizado como um RPG (Role-Playing Game), tipo de jogos em que o jogador assume o comando como protagonista (neste caso, presidente palestino ou chefe de governo israelense), como se fosse um personagem dentro do roteiro. O jogo propõe eventos baseados em fatos reais (ações distintas), nos quais o jogador toma decisões. Porém cada ação tomada reflete na satisfação da população e diversos outros grupos/nações. Sendo possível dialogar com as facções (Hamas, Al-Fatah, Organização para a Liberdade da Palestina (OLP) e Yesha), bem como pedir ajuda para outras nações e organizações (Estados Unidos, o mundo Árabe e Nações Unidas) (Peacemaker, 2014).

Exemplificando a aplicabilidade do jogo, Kampf (2014) desenvolveu um estudo visando a avaliação do PeaceMaker como ferramenta pedagógica que busca a paz no conflito com alunos de ensino fundamental, de uma escola só de meninas palestinas e judias, percebendo que quando jogado individualmente, obteve-se uma menor assertividade na resolução dos conflitos (32 \%) do que os estudantes que estavam em duplas (75\%), que eram compostas de uma aluna judia e uma aluna palestina. A jogabilidade em dupla parece gerar maior discussão, apresentando melhores soluções para o desafio com suas opiniões pessoais, tendo um número maior de ações de cunho político do que de segurança, buscando a resolução dos problemas propostos pelo jogo. $\mathrm{O}$ fato de haver maior participação dos alunos jogando-se em dupla comprova aquilo que fora defendido por Vygotsky acerca da zona de desenvolvimento proximal.

Por mais de uma década, mesmo os pensadores mais sagazes nunca questionaram esse fato; nunca consideraram a noção de que aquilo que a criança consegue fazer com a ajuda dos outros poderia ser, de alguma maneira, muito mais indicativo de seu desenvolvimento mental do que aquilo que consegue fazer sozinha (Vygotsky, 2000, p. $111)$.

O PeaceMaker oferece três graus de dificuldade, em que aumenta-se a quantidade de eventos críticos, fazendo com que as decisões do jogador tenham um 
feedback de aprovação ou reprovação do seu governo com maior frequência. O jogo tem a possibilidade de ser jogado em até três idiomas: árabe, hebraico e inglês.

A Figura 1 apresenta a tela principal do jogo, que tem: (a) o placar de satisfação da população palestina e israelense; (b) gráficos de satisfação com as ações tomadas pelo governo do jogador, do ponto de vista de algum país ou grupos de países, facções extremistas, ONU e grupos militantes; (c) informações de como está o desempenho em alguns setores do seu governo, apontando a segurança, liderança, simpatia com o público e a cooperação com governo palestino ou israelense.

A geografia do jogo apresenta os territórios israelenses, palestino e suas divisões, para facilitar a identificação e auxiliar quando ocorre algum determinado evento, ele apresenta: (d) sinalizações de conflitos, atos de terrorismo e manifestos contra o governo ou (e) manifestos de apoio às ações do governo.

Independente de qual governo o jogador escolha para liderar, estará disponível para ele o тепи de ações, que oferecerá três categorias de tomada de decisão com os eventos do jogo, dentro de cada categoria existe subcategorias, é possível identificar algumas variações nestas subcategorias dependendo de qual líder político o jogador escolha, como visto na Figura 2 (Peacemaker, 2014).

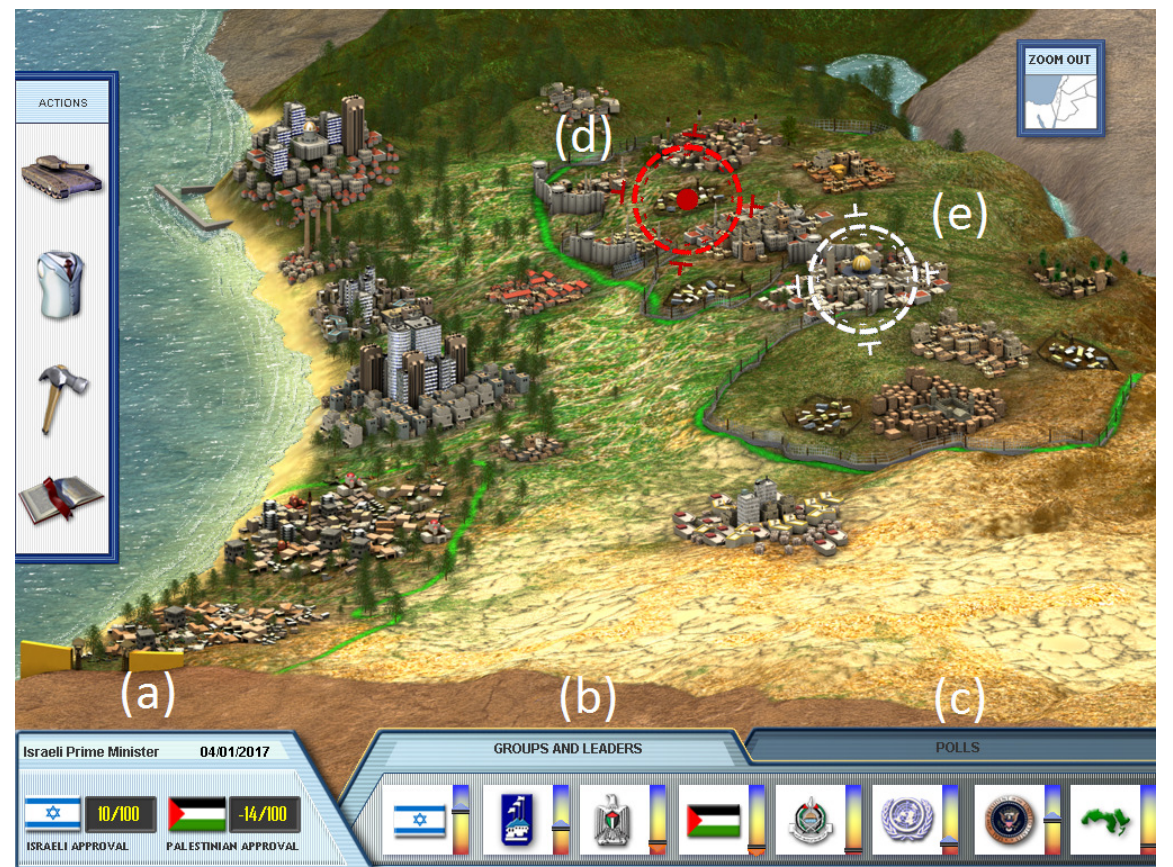

Figura 1 - Tela principal onde ocorre as interações do jogo PeaceMaker: (a) Placar de aprovação, (b) gráfico dos grupos e lideranças, (c) gráfico sobre a satisfação do governo, (d) manifestação negativa do governo e (e) manifestação positiva em prol do governo.

Cada categoria oferecida pelo jogo é destinada para um determinado contexto, são elas: Segurança, através dela é possível administrar a segurança da população e contramedidas para atos de terrorismo e realizar parcerias com as forças armadas palestinas e israelenses; Política, nas ações da aba de política o jogador pode realizar discursos para a sua população, para as lideranças políticas israelense e palestina, líderes mundiais, grupos extremistas nacionais, as Nações Unidas e para o mundo; Construções, oferece ao jogador a possibilidade de realizar investimentos na área da educação, infraestrutura e turismo, na categoria de turismo é possível pedir ajuda de investidores externos ou utilizar recursos do seu governo. 

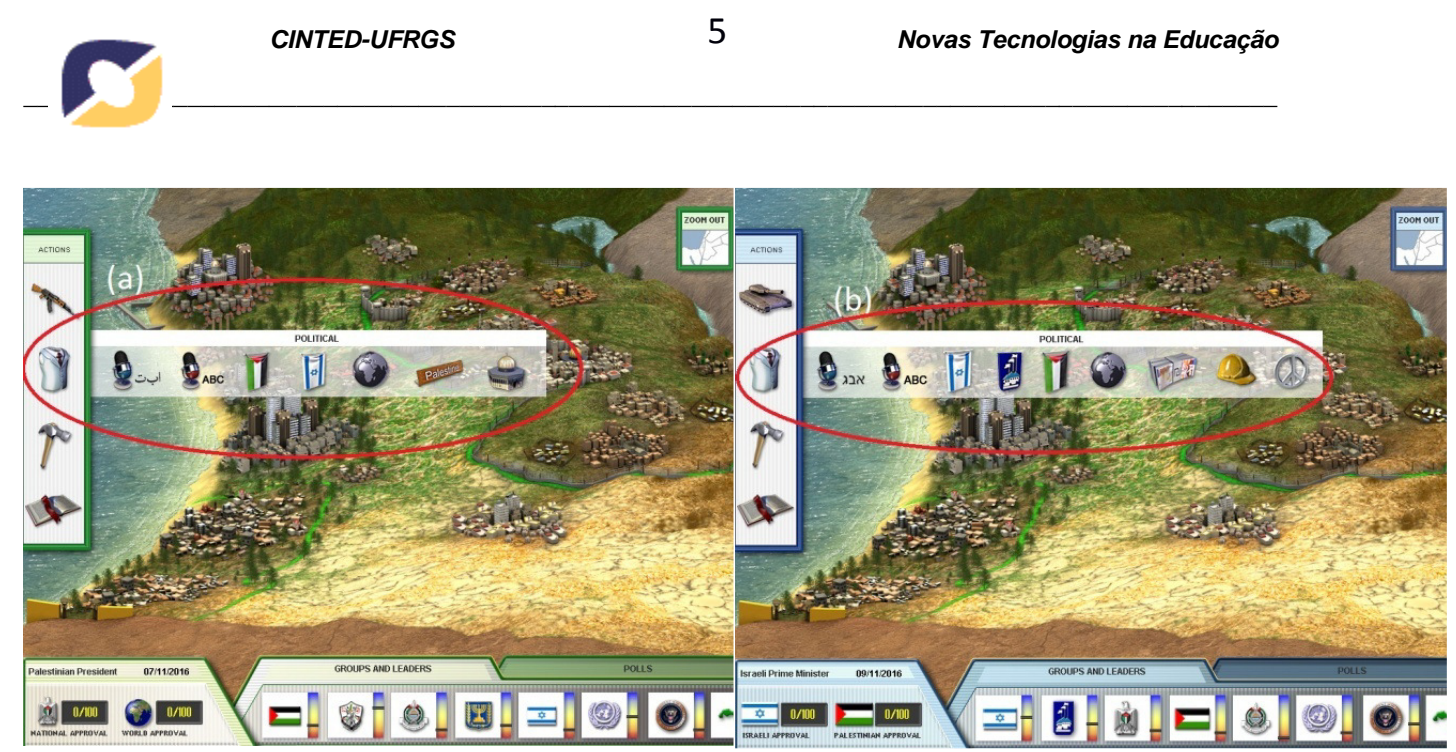

Figura 2 - Tela principal utilizada quando o jogador decide ser o presidente da Palestina (à esquerda) e primeiro ministro de Israel (à direita).

\section{Material e Métodos}

A partir do conceito de interdisciplinaridade foram desenvolvidos planos de aula relacionados a conceitos históricos e geopolíticos contextualizando o aluno ao desafio que lhe é apresentado: encontrar uma solução de paz para o Oriente Médio, onde seja possível a coexistência das duas nações. Para facilitar o uso do jogo fez-se um glossário traduzindo os textos do jogo em língua inglesa.

A maneira em que a metodologia foi pensada e concebida visa alcançar o campo de interesse da maior parte possível do grupo de alunos. Essa oportunidade de trabalhar com diversas matérias, em diferentes óticas e instrumentos, proporciona um maior alcance despertar o interesse dos alunos, levando em consideração as múltiplas inteligências de Gardner (Gardner, 1994), compreendendo a heterogeneidade de uma sala de aula, bem como se buscando alcançar o interesse do maior número de pessoas possível, através das diferentes estratégias, como vídeos, discussões verbais interpessoais, utilização de pensamento lógico e matemático através do game, apresentação de documentário, etc.

Silveira et al. (2015) apresenta uma abordagem mais aprofundada sobre o jogo, avaliando-o como uma alternativa interessante para o estudo de diversos conhecimentos relacionados às disciplinas de história, geografia bem com abordando temas de sociologia, filosofia e psicologia humana, além da necessária leitura dos textos em inglês. Essa referência foi utilizada como base para o desenvolvimento dos assuntos tratados nos planos de aula deste artigo. Além desse referencial não se fez uso de trabalhos relacionados ao uso de jogos RPG computacionais em sala de aula, bem como relacionados aos planos de aula propostos, uma vez que as pesquisas bibliográficas não trouxeram resultados pertinentes.

Foram pensados três planos de aula: 1) um dia inteiro de encontro, dividido em dois períodos de quatro horas; 2) dois encontros de quatro horas, intercalados por uma semana, no primeiro encontro o jogo foi explorado apenas no final, enquanto no segundo encontro o jogo foi explorado no inicio e final; 3) dois encontros de quatro horas, intercalados por uma semana, no qual o jogo é a estratégia inicial do desenvolvimento.

Como ferramenta de avaliação do aprendizado foram aplicados questionários antes, durante e depois da atividade, composto por questões relacionadas ao conflito tema do jogo. Os questionários utilizados podem ser acessados pelo link (https://drive.google.com/open?id=0Bwt2V5pYhKVOTFhOVXhPZUJ3OEk). 


\subsection{Modelo em um único dia}

$\mathrm{Na}$ proposta de apresentação em apenas um dia de atividades, dividem-se os trabalhos em dois turnos de quatro horas cada. No período matutino apresentou-se toda parte teórica: conceitos históricos e geopolíticos através da utilização de recursos tecnológicos (datashow) e apresentação de dois vídeos, sendo um introdutório, sobre os povos que ocuparam a região ao longo da história, e um documentário sobre a criação do estado moderno de Israel e a origem do conflito entre israelenses e palestinos. No final do período matutino, fez-se um test drive, sem direcionamento dos educadores, para que os mesmos entrassem em contato com o jogo sem maiores interferências.

No período vespertino, foi apresentado um glossário dos termos em inglês utilizados ao longo do jogo, para facilitar o entendimento dos alunos e aumentar a jogabilidade. Em seguida, é feita uma explanação geral do jogo e de seus objetivos. Ao longo de todo trabalho, são consideradas pontuações referentes à participação de cada aluno, conforme já apresentado anteriormente.

\subsection{Modelo em dois dias, com apresentação do jogo apenas no segundo dia.}

Também nessa metodologia inicia-se com a apresentação teórica no primeiro dia, conforme apresentado no modelo de único dia, período matutino. Ao longo da semana, foram passadas atividades para que os alunos aprofundassem os conhecimentos apresentados, utilizando para isso a plataforma educacional Edmodo que, basicamente, funciona como uma sala virtual (Edmodo, 2017).

As atividades durante a semana exploraram os seguintes tópicos: resumo das atividades em sala de aula; apresentação dos pontos fracos e os pontos fortes identificados na apresentação teórica; facções e grupos; apresentação de um mapa atualizado da região, apresentando as fronteiras políticas dos territórios palestinos e israelenses; link do jogo, para que os alunos possam conhecê-lo, previamente. Destacase que tais tópicos foram apresentados no modelo de um único dia durante a atividade, utilizando datashow.

No segundo dia, foi apresentado o jogo, primeiramente através de um test drive, sem nenhum direcionamento prévio. A partir de então, foi feita uma apresentação completa do jogo através de suas telas, já apresentando o significado das palavras e expressões em inglês, explicitando o objetivo de se conquistar a coexistência dos dois estados, atingindo tal objetivo através do alcance de alto grau de aprovação das decisões políticas do jogador mediante as nações envolvidas no conflito e das lideranças políticas mundiais.

\subsection{Modelo em dois dias, com apresentação do jogo desde o primeiro dia.}

Nessa metodologia proposta, basicamente, inverte-se a proposta anterior, fazendo com que o jogo seja uma espécie de motivador para que os alunos tenham maior interesse no desenvolvimento das atividades propostas no decorrer da semana, que intermedia os dois dias de encontros.

Assim, a partir do plano de aplicação anterior, o primeiro dia fica dedicado à parte introdutória e à aplicação do jogo, no laboratório, ficando a parte teórica para o segundo encontro. 


\section{Resultados}

As atividades foram realizadas com alunos da turma de $1^{\circ}$ ano do curso técnico em informática do IFG (Instituto Federal de Goiás) campus Inhumas em agosto a novembro de 2015, os alunos tinham média de idade de 15 anos. Participaram 4, 8 e 7 alunos nas atividades dos planos de aula 1, 2 e 3, respectivamente. Esses alunos participaram de todos os dias (e períodos) de atividade. Como a atividade não estava integrada a uma disciplina curricular, e não foi desenvolvida em horário de aula, houve dificuldade na participação de mais alunos.

O jogo desperta o interesse dos alunos, independente da metodologia proposta, sendo que a maioria dos alunos relatou ter se interessado no jogo $(65 \%)$ e gostaram da metodologia proposta $(64 \%)$ principalmente devido à facilidade de aprendizagem que tiveram (60\%). No entanto, alguns alunos relataram a dificuldade com o idioma inglês (12\%) e outros solicitaram jogos mais fáceis (12\%).

Para avaliação de aprendizagem considerou-se questões objetivas e subjetivas dos questionários. Para as questões objetivas as respostas foram compiladas como certo ou errado, com valores 1 e 0 , respectivamente e os resultados somados, resultando em um valor numérico. Para as questões subjetivas foi considerado o intervalo de notas entre 0 e 1 , sendo 1 para a respostas coerente/correta e 0 para não foram preenchidas ou incoerentes/incorretas.

A análise de aprendizado está relacionada ao aluno ter respondido incorreto ou nulo em uma determinada questão, antes de realizar a atividade, e respondeu corretamente, em uma questão de assunto similar, depois da participação na atividade. São quatro análises de aprendizado, sendo: a) início de conflito entre Israel e Palestina; b) sobre os estados palestinos; c) resistência armada; d) diferença social entre palestinos e israelenses.

O motivo da escolha destes itens está relacionado ao objetivo de mensurar o grau de conhecimento dos alunos antes e depois das explanações e apresentação do jogo. São tópicos pertinentes às matérias de geografia e de história que podem ser facilmente identificadas como de domínio ou não dos discentes. Assim, foram elaboradas perguntas semelhantes, equivalentes, tanto no questionário antes, quanto no depois, possibilitando a análise apresentada. A Tabela 1 apresenta as questões utilizadas para as análises de aprendizado dos alunos, relacionando o tema com as questões dos questionários antes e depois da execução da atividade.

Tabela 1 - Questões utilizadas para a análises de aprendizado dos alunos

\begin{tabular}{|c|c|c|}
\hline Tema & Questões antes & Questões depois \\
\hline $\begin{array}{c}\text { Conflito entre Israel e } \\
\text { Palestina }\end{array}$ & $\begin{array}{c}\text { Como o conflito entre Israel } \\
\text { e Palestina começou? }\end{array}$ & $\begin{array}{c}\text { Como o conflito atual, entre } \\
\text { Israel e Palestina, teve início? }\end{array}$ \\
\hline Estados palestinos & $\begin{array}{c}\text { Quantos Estados Palestinos } \\
\text { existem? Justifique sua } \\
\text { resposta. }\end{array}$ & $\begin{array}{c}\text { Como é, atualmente, a } \\
\text { organização territorial do } \\
\text { Estado Palestino? }\end{array}$ \\
\hline Resistência armada & $\begin{array}{c}\text { Como os palestinos e } \\
\text { israelenses justificam o uso } \\
\text { da resistência armada? }\end{array}$ & $\begin{array}{c}\text { O que você pensa que } \\
\text { poderia ser feito em relação à } \\
\text { faixa de Gaza? }\end{array}$ \\
\hline $\begin{array}{c}\text { Diferença social entre } \\
\text { palestinos e israelenses }\end{array}$ & $\begin{array}{c}\text { Existe alguma diferença } \\
\text { social entre qualidade de vida } \\
\text { de cidadãos israelenses e } \\
\text { palestinos? }\end{array}$ & $\begin{array}{c}\text { Existe alguma diferença } \\
\text { social entre qualidade de vida } \\
\text { de cidadãos israelenses e } \\
\text { palestinos? }\end{array}$ \\
\hline
\end{tabular}


Para a análise dos resultados, consideraram-se os seguintes grupos de alunos: grupo 1, alunos que participaram da atividade em um único dia; grupo 2, alunos que participaram da atividade no intervalo de dois dias, com apresentação do jogo apenas no segundo dia; grupo 3, alunos que participaram da atividade no intervalo de dois dias, com apresentação do jogo desde o primeiro dia; grupo $2+3$, alunos que fizeram a atividade no intervalo de dois dias com apresentação do jogo no primeiro dia ou no segundo dia. A Figura 3 apresenta um gráfico comparativo da média dos resultados dos grupos avaliados das questões utilizadas para a análise de aprendizado dos alunos.

Como resultado, os alunos do grupo 1 apresentam maior conhecimento antes da atividade do que os alunos do grupo $2+3(\mathrm{p}<0,001, \mathrm{t}=3,74)$. Já o aprendizado sobre o assunto foi em média menor para o grupo 1 (média $=1,00$ ) e para o grupo $2+3$ (média $=1,33)$, no entanto não é possível confirmar essa diferença estatisticamente $(\mathrm{p}=$ $0,553, \mathrm{t}=-0,60)$.

Em uma análise, considerando o grupo 2 e 3, o conhecimento dos alunos em relação ao assunto, antes da atividade, não pode ser considerado distinto estatisticamente $(\mathrm{p}=0,060, \mathrm{t}=-2,11)$ mas apresentam médias distintas, sendo para o grupo 2 (média $=0,57$ ) menor do que para o grupo 3 (média $=1,60)$, demonstrando que existe uma diferença relativa entre os resultados de aprendizados de ambos os grupos, no entanto, devido à amostragem dos testes, não pode ser comprovada estatisticamente. Já o aprendizado sobre o assunto foi em média maior para o grupo 3 (média $=1,40$ ) do que para o grupo 2 (média $=1,28$ ), no entanto não é possível confirmar essa diferença estatisticamente $(\mathrm{p}=0,553, \mathrm{t}=-0,60)$. Da mesma forma que o teste anterior, existe uma diferença relativa entre os resultados de aprendizados de ambos os grupos, no entanto, devido à amostragem dos testes, não pode ser comprovada estatisticamente.

Para os alunos que participaram do grupo 3 percebeu-se que as partes teóricas unidas ao jogo, bem como a utilização de todos os conteúdos propostos durante o decorrer da semana atraíram mais a atenção dos alunos e trouxeram um pouco de ansiedade para terem um segundo momento com o jogo, fazendo com que eles tivessem um maior nível de concentração em cumprir a proposta de trazer a paz para o conflito, como um pacificador.

Avaliando alguns detalhes, a partir das respostas aos questionários, observou-se que os alunos do grupo 3 apresentam opiniões que corroboram para considerar a opção pelo modelo em dois dias com apresentação do jogo desde o primeiro dia, como o melhor plano de aula: todos os alunos do grupo 3 (100\%) consideraram que não há necessidade de alteração do plano de aula, pois realmente facilita o aprendizado, diferente da opinião dos alunos do grupo 2, que apresentaram dificuldade no idioma (29 $\%)$ ou queriam um jogo mais fácil $(14 \%)$ e do grupo 1 , que solicitaram melhor distribuição da atividade (25\%) e queriam um jogo mais fácil (25\%).

Isso demonstra que a participação dos alunos em atividades práticas facilita o aprendizado. A visão piagetiana de que o aluno aprende de maneira mais construtiva melhora sua construção de conceitos.

Para Piaget, o conhecimento não é uma qualidade estática e sim uma relação dinâmica. A forma de um indivíduo abordar a realidade é sempre uma forma construtiva e, portanto tem a ver com sua disposição, com o seu conhecimento anterior e com as características do objeto (Goulart, 1998, p. 17). 

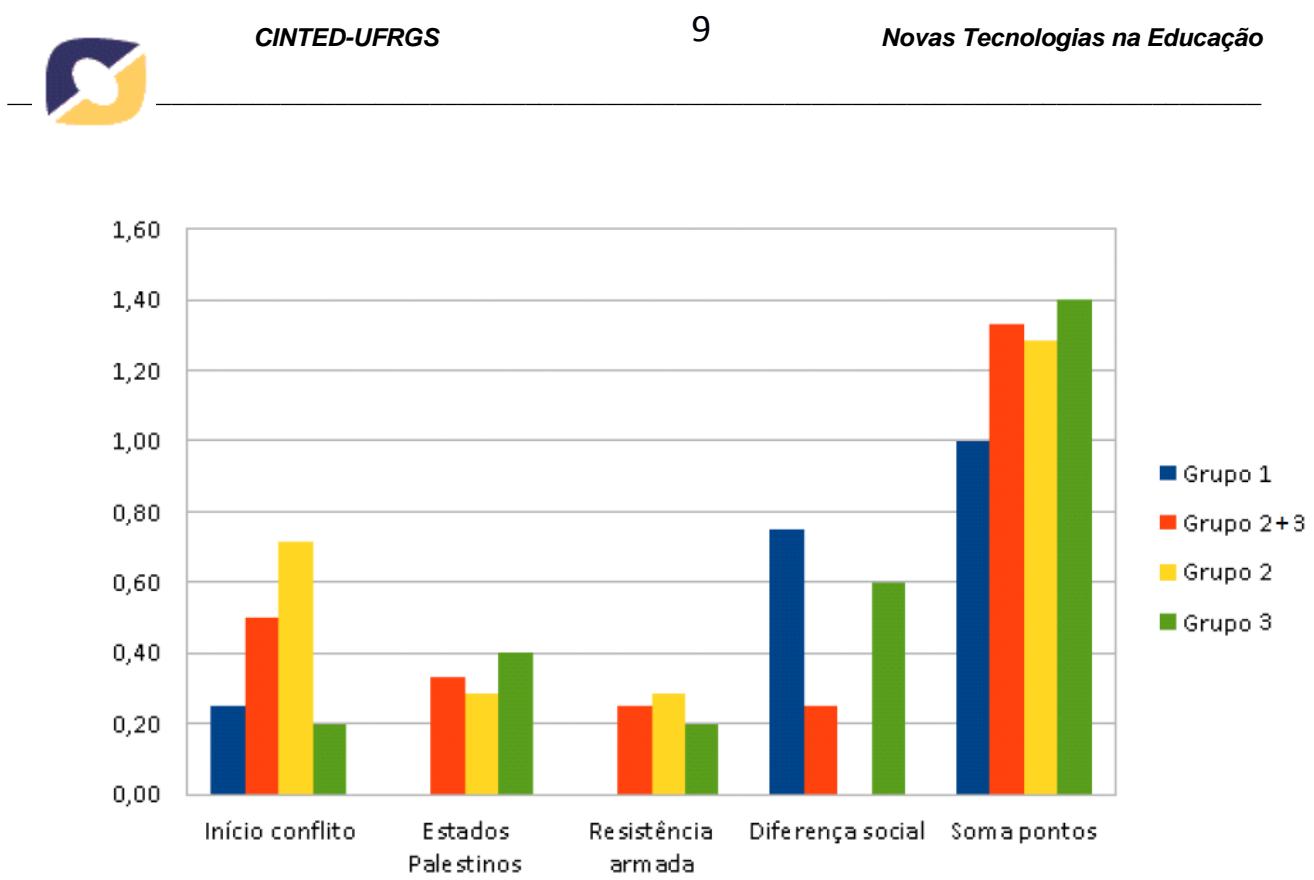

Figura 3 - Gráfico comparativo da média dos resultados das questões utilizadas para as análises de aprendizado, para os grupos 1, 2, 3 e $2+3$.

Percebeu-se que as partes teóricas unidas ao jogo, bem como a utilização de todos os conteúdos propostos durante o decorrer da semana, atraíram a atenção dos alunos e trouxeram um pouco de ansiedade para terem um segundo momento com o jogo, fazendo com que eles tivessem um maior nível de concentração em cumprir a proposta de trazer a paz para o conflito, como um pacificador.

\section{Conclusões}

Este artigo propôs avaliar uma estratégia de ensino que pudessem, a exemplo do sugerido por Freire (1996), estimular a curiosidade dos alunos através de uma prática interdisciplinar, utilizando-se de recursos de maior interesse dos alunos. Neste caso, utilizou-se o PeaceMaker como entretenimento rico em conteúdo, que possibilitou uma integração de saberes, envolvendo conteúdo que proporciona o diálogo de diferentes disciplinas em uma única atividade, estimulando os alunos a explorar tudo aquilo que vivenciam no jogo.

Unir diferentes disciplinas em mesmo objeto a ser trabalhado em uma sala de aula, debatendo mesmo em diferentes óticas da interdisciplinaridade, oferece aos alunos uma maior abrangência e possibilidade de prender a atenção dos mesmos, melhorando sua aprendizagem, e aprimorando o processo de ensino-aprendizagem.

Em média, o plano de aula em dois dias, com apresentação do jogo desde o primeiro dia, apresentou maior aprendizado pelos alunos, devido maior envolvimento com a atividade durante a semana bem como menos dificuldade no desenvolvimento da atividade. No entanto, seria interessante realizar o experimento com uma amostra maior de alunos, para assim validar estatisticamente.

Através dos resultados apresentados, pode-se afirmar que a utilização de jogos educacionais é uma ótima alternativa de planejamento de aulas dinâmicas, atendendo aos anseios de alunos nativos digitais, como afirma Mattar (2010), que já não se contentam com a forma tradicional de ensino, utilizando-se apenas as ferramentas básicas livro, quadro e explanação do professor. Vale salientar que o primordial será sempre a criatividade do professor e o conhecimento deste referente à sua turma de alunos, buscando identificar as melhores estratégias de ensino. 


\section{Referências}

EDMODO. Home Page. Disponível em: www.edmodo.com. Acesso: jun. 2017.

GOULART, Iris Barbosa. A Educação na perspectiva construtivista: reflexões de uma equipe interdisciplinar. Petrópolis, RJ: Vozes, 1998.

GARDNER, Howard. Estruturas da mente: a Teoria das Múltiplas Inteligências. Porto Alegre: Artes Médicas, 1994.

KAMPF, R. Are two better than one? Playing singly, playing in dyads in a computerized simulation of the Israeli-Palestinian conflict. Computers in Human Behavior, 32, 9-14, 2014. doi:10.1016/j.chb.2013.11.005.

MATTAR, João. Games em educação: Como os nativos digitais aprendem. São Paulo: Pearson Prentice Hall, 2010.

MEKSENAS, Paulo. Sociologia da Educação. São Paulo: Edições Loyola, 2007;

MORAES, Dênis de. A comunicação sob domínio dos impérios multimídias. In: DOWBOR, Ladislau et al. Desafios da Comunicação. Petrópolis, RJ: Vozes, 2000.

OLIVEIRA, J.B.A (org). Perspectivas da Tecnologia Educacional. São Paulo: Pioneira, 1977.

PEACEMAKER. Home Page. Disponível em: http://www.peacemakergame.com/. Acesso: out. 2014.

PIAGET, J. Para onde vai a educação?. Rio de Janeiro: José Olympio, 1974

SAVIANI, D. Escola e Democracia. 2a Edição. São Paulo: Cortez, 1984.

SILVEIRA, C. R.; PACHECO, M. G.; FERREIRA, S. A.; BARRA, A. S. B.; TEIXEIRA, R. A. O jogo Peacemaker como ferramenta educacional para professores de geografia, história, inglês, sociologia e filosofia: uma análise interdisciplinar a partir do conflito entre Israel e Palestina. Enciclopédia Biosfera, 11 (20), 532 - 544, 2015.

TECH MUNDO. Carmen Sandiego: conheça curiosidades e polêmicas dos jogos da série. Disponível em: http://www.techtudo.com.br/noticias/noticia/2015/12/carmensandiego-conheca-curiosidades-e-polemicas-dos-jogos-da-serie.html. Acesso: jul. 2017.

VYGOTSKY, L. Interação entre aprendizado e desenvolvimento. In: A Formação Social da Mente. São Paulo, Martins Fontes, $6^{\circ}$ Edição, 2000, 179p. 